\title{
Dissipation of Impact Stress Waves within the Artificial Blasting Damage Zone in the Surrounding Rocks of Deep Roadway
}

\author{
Jianguo Ning, Jun Wang, Yunliang Tan, and Xinshuai Shi \\ State Key Laboratory of Mining Disaster Prevention and Control Cofounded by Shandong Province and \\ the Ministry of Science and Technology, Shandong University of Science and Technology, Qingdao 266590, China
}

Correspondence should be addressed to Jun Wang; wangjunsdkjd@126.com

Received 18 November 2015; Revised 29 February 2016; Accepted 21 March 2016

Academic Editor: Toshiaki Natsuki

Copyright (C) 2016 Jianguo Ning et al. This is an open access article distributed under the Creative Commons Attribution License, which permits unrestricted use, distribution, and reproduction in any medium, provided the original work is properly cited.

Artificial explosions are commonly used to prevent rockburst in deep roadways. However, the dissipation of the impact stress wave within the artificial blasting damage zone (ABDZ) of the rocks surrounding a deep roadway has not yet been clarified. The surrounding rocks were divided into the elastic zone, blasting damage zone, plastic zone, and anchorage zone in this research. Meanwhile, the ABDZ was divided into the pulverizing area, fractured area, and cracked area from the inside out. Besides, the model of the normal incidence of the impact stress waves in the ABDZ was established; the attenuation coefficient of the amplitude of the impact stress waves was obtained after it passed through the intact rock mass, and ABDZ, to the anchorage zone. In addition, a numerical simulation was used to study the dynamic response of the vertical stress and impact-induced vibration energy in the surrounding rocks. By doing so, the dissipation of the impact stress waves within the ABDZ of the surrounding rocks was revealed. As demonstrated in the field application, the establishment of the ABDZ in the surrounding rocks reduced the effect of the impactinduced vibration energy on the anchorage support system of the roadway.

\section{Introduction}

South Africa, Poland, Russia, Canada, Australia, and others have gradually begun to mine their deeper coal resources. However, while exploiting deep coal resources, rock burst occurs more often and with greater intensity in mine roadways. According to relevant statistics, approximately $80 \%$ of rock burst occurs in the roadways of deep coal seams annually [1]. Rock burst is usually a sudden outburst, giving rise to vibration and damage in coal and rock masses. Meanwhile, its energy is expected to eject coal and rock masses so as to block the roadway, leading to collapse and damage to supports and equipment in the stope, as well as casualties. The control of rock burst in deep roadways has been an important topic in the past few years $[2,3]$.

When the excavation in a deep roadway becomes stable, the fractured zone, plastic zone, and elastic zone are expected to be generated in the surrounding rocks: a large elastic strain energy usually accumulates at the junction of the elastic and plastic zones $[4,5]$. Disturbed by the mining of the working face, the elastic strain energy is expected to be spread to the roadway surface in the form of stress waves (the impactinduced vibration energy). When the support system of the roadway (the supporting layer constituted by the anchorage zones of the bolt and anchor cable) cannot resist the impactinduced vibration energy generated by the stress waves, a rock burst occurs [6].

When a deep roadway is excavated, the radii of the fractured zone and the plastic zone in the surrounding rocks are affected by many factors, such as the ground stress, the radius of the roadway, and the support resistance of the support. As a matter of fact, the thicknesses of the fractured zone and the plastic zone formed naturally after the excavation usually fail to meet anti-impact requirements. Therefore, pressure relief technology using large diameter drill holes [7], artificial explosions [8], and coal seam water infusion [9] can be used to smash the surrounding rocks. The thickness of the fractured zone and the size of the fractured coal and rock masses are, therefore, regulated artificially, forming an anti-impact system with favourable energy absorption and cushioning performance. The system can absorb the energy released by stress waves and, therefore, provide ideal anti-impact effects. 

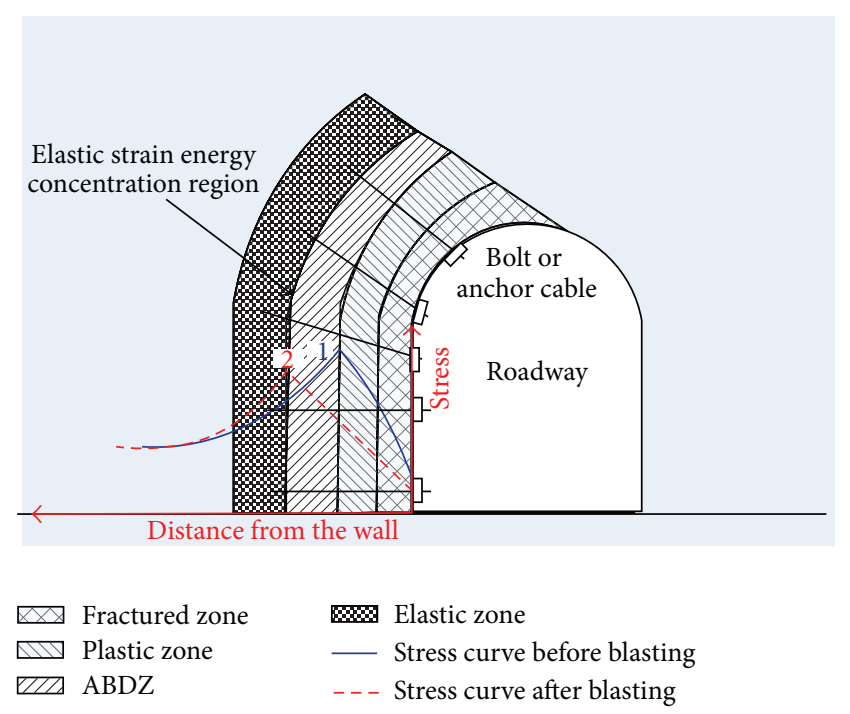

FIGURE 1: Stress distribution in the surrounding rocks with the $\mathrm{ABDZ}$ of the deep roadway.

As for artificial explosions used to prevent rock burst, firstly, the drilling rig is usually employed to drill boreholes in the surrounding rocks. Then, explosives are placed in the borehole (usually at the junction of the elastic and plastic zones) before the borehole is sealed. While the artificial blasting damage zone (ABDZ) was established in the surrounding rocks, concentrated elastic strain energy can be transferred to greater depth. Besides, when the elastic strain energy is disturbed and spread outward in the form of stress waves, the fractured coal and rock masses in the ABDZ can dissipate some of the impact stress waves energy [10], as shown in Figure 1. In addition, the support system constituted by flexible energy absorption devices, such as the bolt and anchor cable outside the ABDZ, can resist the rest of energy, thus preventing the rock burst successfully [11].

However, the dissipation of impact stress waves in the fractured coal and rock masses inside the ABDZ is unclear. As a result, the artificial explosions adopted by many mines have difficulty in preventing rock burst.

Based on the fractured structures of the coal and rock masses in the ABDZ, a simplified model of the normal incidence of the impact stress waves was established. In this way, the attenuation coefficient of the amplitude of the impact stress waves was obtained after the waves passed through the ABDZ. Meanwhile, a numerical simulation was used to reveal the dissipation of the impact stress waves in the ABDZ. Thereafter, the model was verified in the field.

\section{Simplified Model of the Normal Incidence of Impact Stress Waves}

After the detonation of the spherical explosive cartridge in the surrounding rocks, the pulverizing zone, fractured zone, and crack zone were, respectively, generated from the inside out in the rock mass near the explosive cartridge [12]. This zonal structure caused by the explosion of a single explosive
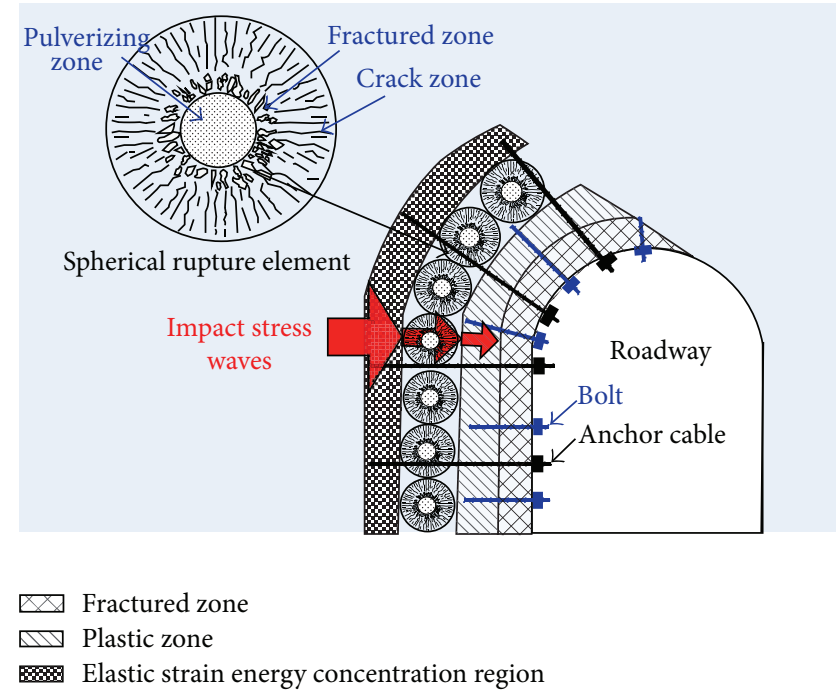

FIGURE 2: Simplified model of the normal incidence of the impact stress waves.

cartridge is called the "spherical rupture element." Moreover, the spherical rupture elements are supposed to constitute the ABDZ (Figure 2).

As for a single spherical rupture element, when the elastic strain energy within the surrounding rocks is disturbed by mining, it is supposed to be spread in the coal mass in the form of impact stress waves. In this process, the impact stress wave is expected to pass through the crack zone, the fractured zone, and the pulverizing zone of the spherical rupture element in sequence and then pass through these zones again. At last, it enters into anchorage support zone of the roadway. Owing to the rupture element being spherical and assuming that the impact stress waves vertically penetrate the subareas of each rupture element in the ABDZ during their propagation, the waves finally act on the anchorage zone.

\section{The Attenuation Coefficients of the Impact Stress Waves within the Intact Rock Mass and the ABDZ in the Surrounding Rocks}

3.1. The Propagation and Attenuation Coefficient of the Impact Stress Waves within Intact Rock Mass. After being disturbed by mining, the elastic strain energy in the surrounding rocks of the deep roadway is expected to be propagated in the rock masses in the form of stress waves. Assuming that the intact rock mass within the surrounding rocks follows Kelvin-Voigt viscoelastic body behaviour, the amplitude of the stress waves at each point in the rock mass is expected to decrease with increasing propagation distance and time. The two attenuation effects are called spatial and temporal attenuation, respectively [13].

The governing equation of the stress waves in a KelvinVoigt viscoelastic body is expressed as

$$
\rho_{0} \frac{\partial^{2} d}{\partial t^{2}}=E_{V} \frac{\partial^{2} d}{\partial x^{2}}+\eta_{V} \frac{\partial^{3} d}{\partial x^{2} \partial t},
$$


where $E_{V}, \eta_{V}$, and $t$ are the elastic modulus, viscosity coefficient, and time, respectively, $d$ is the displacement of the stress waves along the propagation direction $x$, and $\rho_{0}$ is the density of the intact rock mass.

Suppose that the distance between the vibration source and the particle is $x$, and according to the harmonic wave equation, the amplitude attenuation of the wave at a certain point of the rock can be expressed as follows:

$$
d(x, t)=A e^{i(\omega t-k x)},
$$

where $A$ and $\omega$ are the amplitude and angular frequency and $k$ is the responsive wave number of the stress waves in the coal and rock mass. By combining (1) and (2), the attenuation coefficients $\left(\alpha_{t}\right.$ and $\left.\alpha_{s}\right)$ of the amplitude of the stress waves in a Kelvin-Voigt viscoelastic body, varying with time and space, are given by

$$
\begin{aligned}
& \alpha_{t}=\frac{\eta_{V} E_{V} \omega^{2}}{4\left(E_{V}^{2}+\eta_{V}^{2} \omega^{2}\right)}\left(\sqrt{1+\frac{\eta_{V}^{2} \omega^{2}}{E_{V}^{2}}}+1\right), \\
& \alpha_{s}^{2}=\frac{\rho_{0} E_{V} \omega^{2}}{2\left(E_{V}^{2}+\eta_{V}^{2} \omega^{2}\right)}\left(\sqrt{\left.1+\frac{\eta_{V}^{2} \omega^{2}}{E_{V}^{2}}-1\right) .}\right.
\end{aligned}
$$

Therefore, the amplitude $A$ of the stress waves with propagation distance $(L)$ and time $(T)$ in the intact rock mass can be expressed as

$$
A=A_{0} \cdot e^{-\alpha_{s} L} \cdot e^{-\alpha_{t} T},
$$

where $A_{0}$ represents the initial amplitude of the impact stress waves.

3.2. The Attenuation Coefficients of the Impact Stress Waves in the $A B D Z$. Since the impact stress waves are projected vertically into the ABDZ, a microcuboidal element is separated from the spherical rupture element in the ABDZ. When the stress waves are propagated to the ABDZ, they are expected to pass through the crack zone, fractured zone, and pulverizing zone of the spherical rupture element in sequence and then pass through these zones again in the opposite order. At last, it acted on the anchorage zone of the roadway. Meanwhile, the stress waves are expected to generate complicated transmission and reflection phenomena between the subareas of the blasting damage zone [14], which will affect the propagation and attenuation of the wave stress in the rock mass (Figure 3 ). When the stress waves vertically enter the intact rock mass and the interface of the blasting damage zone $F_{1}$, part of the stress waves (with amplitude $A_{R 1}$ ) will be transmitted through the partitioning interface $F_{1}$. Then, these waves are expected to generate the catadioptric phenomenon on interfaces $F_{1}$ and $F_{2}$ (the interface between the crack zone and the fractured zone in $\mathrm{ABDZ}$ ), while some parts of the stress waves are expected to be transmitted through the interface $F_{2}$ (the amplitudes of the reflected waves and transmitted waves are $A_{R 2}^{\prime}$ and $A_{R 2}$, resp.) and then continue to be spread to the interface $F_{3}$. Afterwards, the stress waves continue to be propagated in additional zone of $\mathrm{ABDZ}$ according to the aforementioned order. Finally, the amplitude of the transmitted waves at the interface $F_{6}$ is $A^{\prime}$.

Assume that $v_{0}, v_{1}, \ldots, v_{4}$ are the velocities of the stress waves within the intact rock mass, crack zone, fractured zone, and pulverizing zone, respectively, and $\rho_{0}, \rho_{1}, \ldots, \rho_{4}$ are the densities of the intact rock mass, crack zone, fractured zone, and pulverizing zone, separately. When the stress waves are propagated from the intact rock mass to the anchorage zone, its transmission coefficients on interfaces $F_{1}, F_{2}, F_{3}, F_{4}$, $F_{5}$, and $F_{6}$ are $f_{1}, f_{2}, f_{3}, f_{4}, f_{5}$, and $f_{6}$, respectively. The widths of the intact rock mass, crack zone, fractured zone, and pulverizing zone are $\Delta r_{0}, \Delta r_{1}, \Delta r_{2}$, and $\Delta r_{3}$, separately. The initial wavelength of the stress waves is $\lambda$.

In accordance with other studies [15], the reflection frequency of the stress waves within the jointed rock mass is determined by the ratio of the wavelength to the width of the joint layer $\lambda / \Delta r_{i}(i=1,2,3)$, as shown in

$$
n=\frac{v_{i+1} \lambda}{v_{i} \Delta r_{i}} \text {. }
$$

When the stress waves are transmitted through the joint layer $F_{1}$ for the first time, the attenuation rate of the amplitude is $\left(\Delta A_{T}\right)_{1}$. After $n$ reflections (assuming that $n$ is an even number) between interfaces $F_{1}$ and $F_{2}$, the amplitude of the stress waves is

$$
A_{R 1}=A\left(\Delta A_{T}\right)_{1} \sum_{k=0}^{n / 2} f_{1}^{k / 2} f_{2}^{k / 2} .
$$

According to the literature [15], the amplitude of the stress waves in mine rocks can be expressed as

$$
A_{T}=\frac{C}{r^{\alpha_{s}}}
$$

where $\alpha_{s}, r$, and $C$ are the spatial attenuation index, the propagation distance of the stress waves, and a constant value, respectively. According to (7), we obtain

$$
\left(\Delta A_{T}\right)_{i}=C \cdot\left[\frac{1}{\left(n \Delta r_{i}\right)^{\alpha_{s}}}-\frac{1}{\left((n-1) \Delta r_{i+1}\right)^{\alpha_{s}}}\right] \text {. }
$$

Let $\left(\Delta A_{T}\right)_{i}=T_{i}(i=1,2,3,4,5)$; thereinto, $\Delta r_{4}=\Delta r_{2}$ and $\Delta r_{5}=\Delta r_{1}$.

After passing through the crack zone, the total amplitude $A_{R 1}$ of the attenuated stress waves is

$$
A_{R 1}=T_{1} A \sum_{k=0}^{n / 2} f_{1}^{k} f_{2}^{k}
$$

Similarly, after passing through the rock masses in the crack zone, fractured zone, and pulverizing zone and entering the anchorage zone by taking the reverse journey, the amplitude of the stress waves is given by

$$
A^{\prime}=A T_{1} T_{2} T_{3} T_{4} T_{5} \sum_{k=0}^{n / 2} f_{1}^{k} f_{2}^{k} \sum_{k=0}^{n / 2} f_{3}^{k} f_{4}^{k} \sum_{k=0}^{n / 2} f_{5}^{k} f_{6}^{k},
$$

where $f_{1}, f_{2}, f_{3}, f_{4}, f_{5}$, and $f_{6}$ can be obtained from large diameter Split-Hopkinson pressure bar tests on rock masses with different amounts of fracturing. 


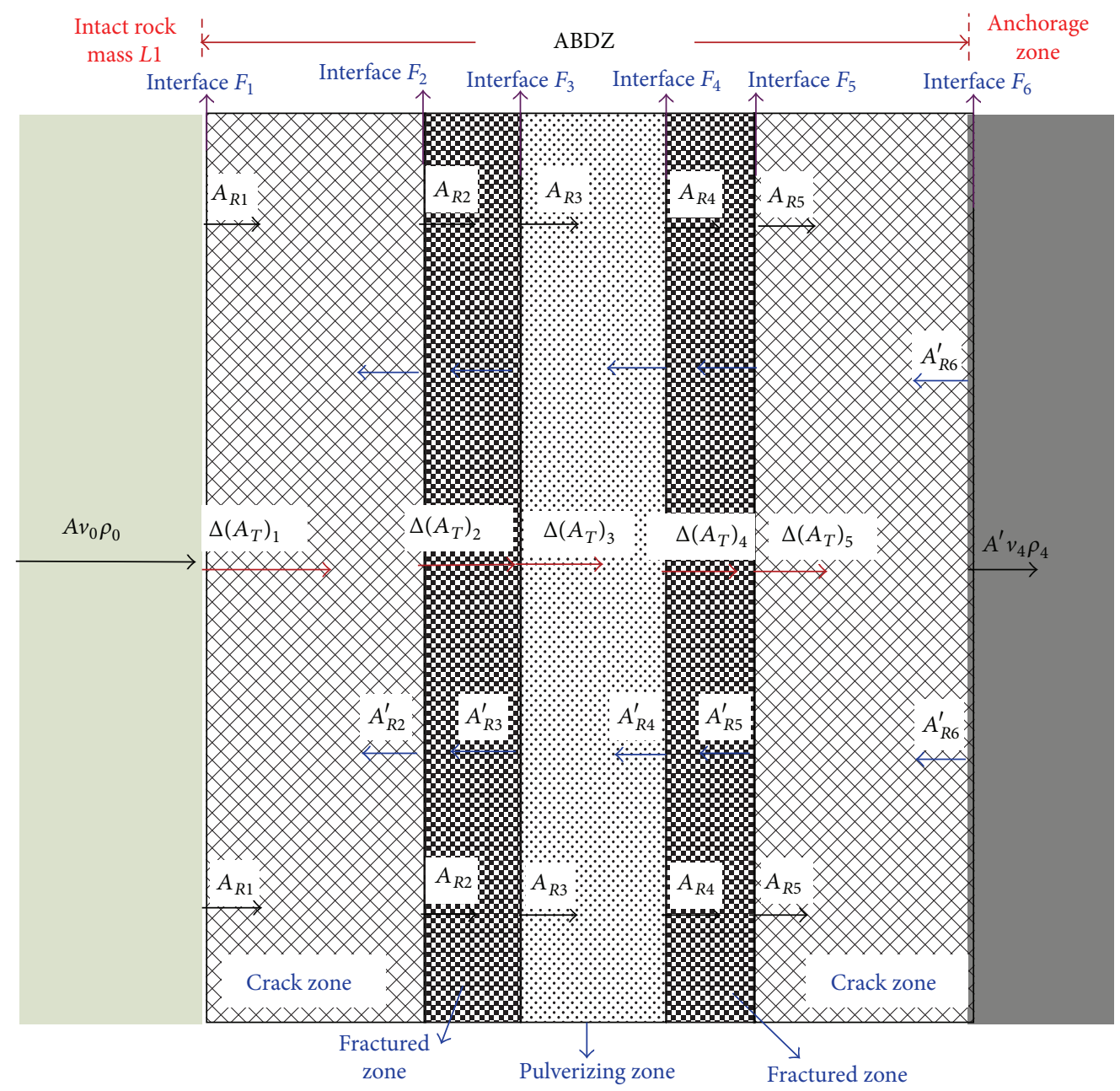

FIgURE 3: The incidence and reflection of a stress wave on the interface of the joint layer.

\section{Numerical Simulation of the Energy Dissipation in the ABDZ}

4.1. Geological and Mining Conditions in the Field. The 2304 working face in Tangkou coal mine (Zibo Mining Group Co., Ltd., Shandong Province, China) is located in the third coal seam with a burial depth of $1,000 \mathrm{~m}$. In addition, the thickness of the coal seam ranges from $2.5 \mathrm{~m}$ to $3.5 \mathrm{~m}$ with an average thickness of $3.0 \mathrm{~m}$, the dip angle of the coal seam ranges from $1^{\circ}$ to $8^{\circ}$ with an average dip of $6^{\circ}$, and the Protodyakonov coefficient of the coal is 0.7 . The 2304 working face is located at the north flank of the western return airway and its south is the 2303 working face which is mining currently. There is no excavation at its north area. At present, the 2304 working face has not yet been mined, and its ventilation roadway is under excavation (Figure 4). Fully mechanised mining of the inclined retreating longwall is used: the strike and inclination lengths being $200 \mathrm{~m}$ and 1,700 $\mathrm{m}$, respectively.

The 2304 ventilation roadway is excavated in a rectangular section, which is $4 \mathrm{~m}$ long, $3 \mathrm{~m}$ wide, and supported permanently by cable anchors (Figure 5). Besides, thread steel resin bolts containing no longitudinal reinforcement with diameters and lengths of $20 \mathrm{~mm}$ and $2,400 \mathrm{~mm}$, respectively, are used in the roof. The bolts, each of which is fixed using two CK2850 resin anchor agents, are arranged with row and line spacings on an $800 \times 800 \mathrm{~mm}$ grid. The anchor cables, which are $17.8 \mathrm{~mm}$ in diameter and 9,000 $\mathrm{mm}$ long, are set with the intervals in the rows and line spacings being $1,200 \mathrm{~mm}$ and $1,600 \mathrm{~mm}$, respectively. Moreover, three CK2350 resin anchor agents are placed into each hole for end anchorage. Thread steel resin bolts without longitudinal reinforcement are used on the walls of the roadway. The bolts have a diameter and length of $20 \mathrm{~mm}$ and 2,200 $\mathrm{mm}$, respectively, and are fixed at $800 \mathrm{~mm}$ intervals (both row and line spacings). In addition, the $100 \times 100 \mathrm{~mm}$ reinforcing mesh is made of reinforcing bars with a diameter of $6.5 \mathrm{~mm}$. The length, width, and thickness of the steel strip are $3,600 \mathrm{~mm}, 80 \mathrm{~mm}$, and $5 \mathrm{~mm}$, respectively.

As shown in Figure 4, the 2304 ventilation roadway has been excavated for a length of $1,300 \mathrm{~m}$. During roadway excavation, dynamic accidents such as the projection of coal and rock masses and the collapse of the roof and the wall of roadway took place frequently.

The TDS- 6 microseismic acquisition system was used to monitor and collect the signal from the impact stress waves in the heading face of the 2304 ventilation roadway every $0.2 \mathrm{~ms}$. 


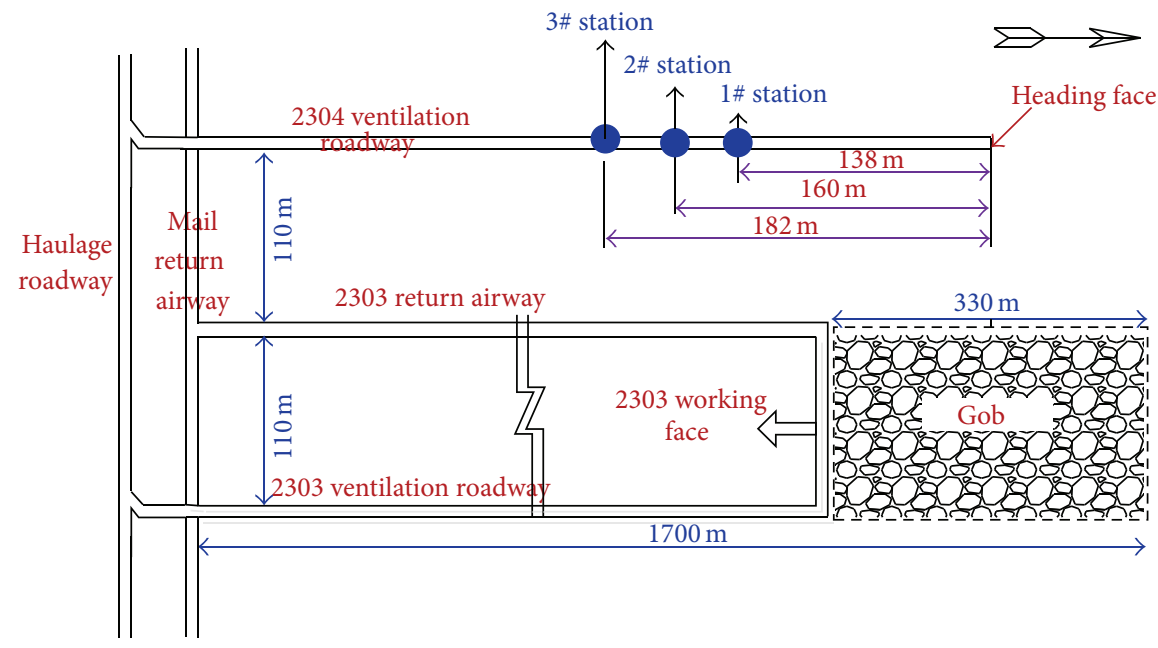

FIGURE 4: Plan layout of the working face.

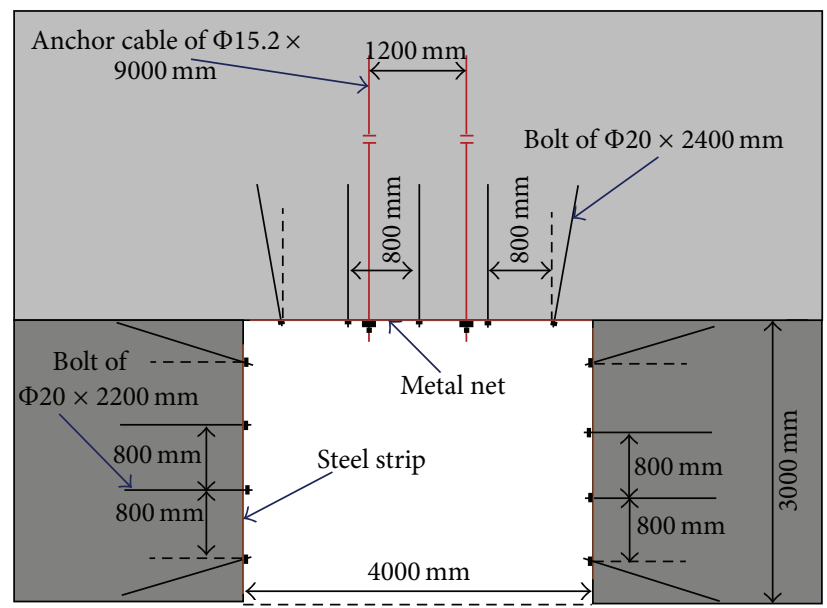

(a) Support profile

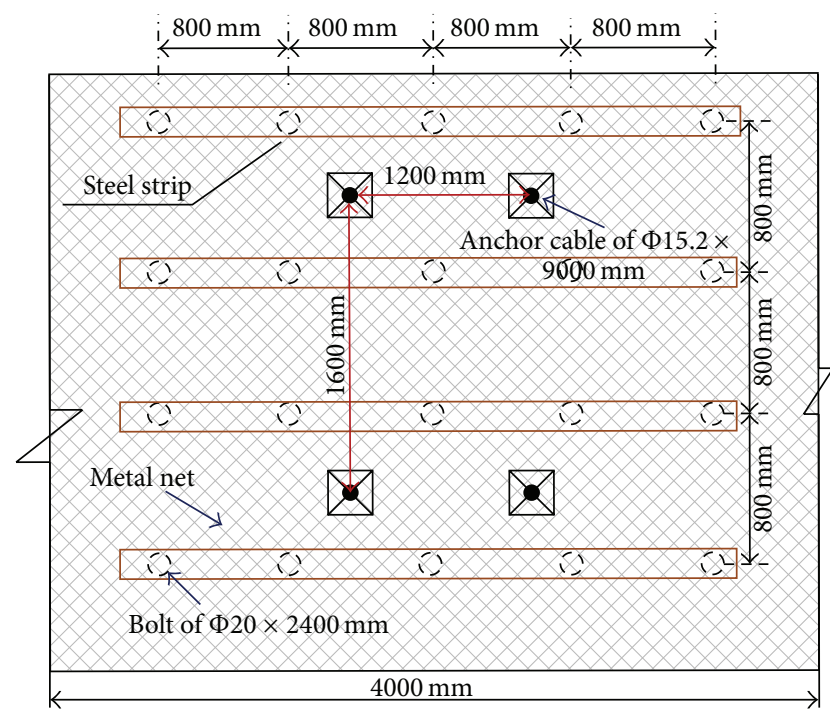

(b) Top view of the support

FIGURE 5: Support scheme for the 2304 ventilation roadway.

After these collected signals were processed, the velocity-time curves of the signals of the impact stress waves were obtained (Figure 6(a)). To simplify the study, the harmonic stress wave with the maximum vibration velocity and shortest period was selected from the curves obtained above (Figure 6(b)). Then, the selected harmonic stress curve was applied as the impact stress wave acting on the surrounding rocks of the roadway for two periods of the numerical simulation.

Rock cores were obtained in the field by drilling. Meanwhile, laboratory testing to find the rock mechanical parameters was carried out according to the Standard for Tests Method of Engineering Rock Masses (GB/T 50266-2013). The lithology and mechanical parameters of the roof and floor are summarised in Table 1.

4.2. Establishment of the Model and Simulation Schemes. Based on the geological and mining conditions of the 2304 ventilation roadway, the dissipation of the impact-induced vibration energy in the ABDZ was studied. Meanwhile, FLAC $^{3 \mathrm{D}}$ was used to establish a numerical calculation model, whose length, width, and height were $52 \mathrm{~m}, 10 \mathrm{~m}$, and $34 \mathrm{~m}$, respectively. The width, height, and length of the roadway were $4 \mathrm{~m}, 3 \mathrm{~m}$, and $10 \mathrm{~m}$, respectively. According to in situ stress measurements on the 2304 ventilation roadway, the rock stress was mainly geostatic at $25 \mathrm{MPa}$ in the vertical direction and $32.5 \mathrm{MPa}$ in the horizontal direction (the lateral pressure coefficient being 1.25). Therefore, horizontal restraint was applied to the $X$ - and $Y$-directions of the model, while the bottom of $Z$-direction was fixed [16]. Besides, the vertical stress $\gamma h$ of $25 \mathrm{MPa}$ generated by the self-weight of the overlying strata was imposed on the top boundary. When the calculation reaches a balance after the excavation process, the impact stress waves were imposed. During the simulation, the static boundary was set and an observation line established 
TABLE 1: The lithology and mechanical parameters of the roadway roof and floor.

\begin{tabular}{|c|c|c|c|c|c|c|c|}
\hline Rock strata & $\begin{array}{l}\text { Thickness } \\
\text { (m) }\end{array}$ & $\begin{array}{c}\text { Density } \\
\left(\mathrm{kg} \cdot \mathrm{m}^{-3}\right)\end{array}$ & $\begin{array}{c}\text { Shear } \\
\text { modulus } \\
(\mathrm{GPa})\end{array}$ & $\begin{array}{c}\text { Bulk } \\
\text { modulus } \\
(\mathrm{GPa})\end{array}$ & $\begin{array}{c}\text { Cohesion } \\
(\mathrm{MPa})\end{array}$ & $\begin{array}{c}\text { Tensile } \\
\text { strength } \\
(\mathrm{MPa})\end{array}$ & $\begin{array}{c}\text { Friction angle } \\
\left(\left(^{\circ}\right)\right.\end{array}$ \\
\hline $\begin{array}{l}\text { Fine } \\
\text { sandstone }\end{array}$ & 19.0 & 2740 & 9.43 & 13.64 & 4 & 6 & 36 \\
\hline $\begin{array}{l}\text { Coarse } \\
\text { sandstone }\end{array}$ & 3.0 & 2520 & 5.41 & 6.65 & 3.33 & 5.4 & 38 \\
\hline Coal seam & 5.0 & 1340 & 1.52 & 4.22 & 2.4 & 1.0 & 18 \\
\hline Mudstone & 1.0 & 2100 & 25.8 & 11.43 & 13.4 & 5 & 7 \\
\hline $\begin{array}{l}\text { Fine } \\
\text { sandstone }\end{array}$ & 6.0 & 2740 & 9.43 & 13.64 & 4 & 6 & 36 \\
\hline
\end{tabular}

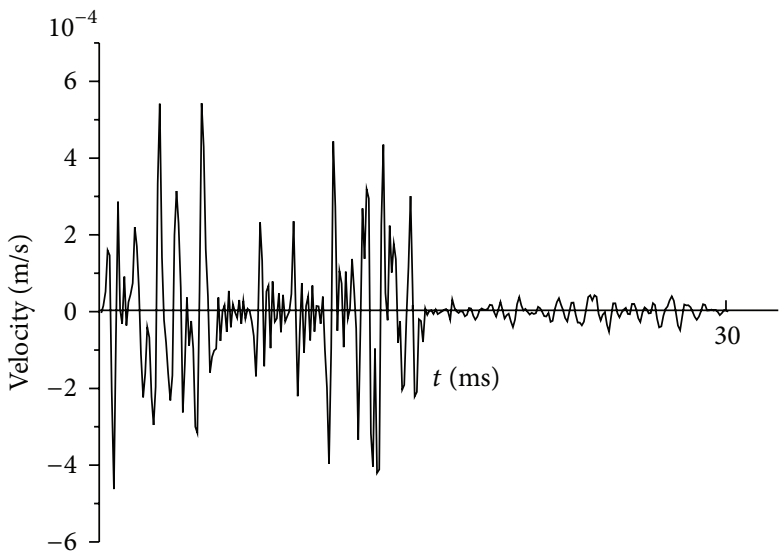

(a) The signal of the impact stress waves

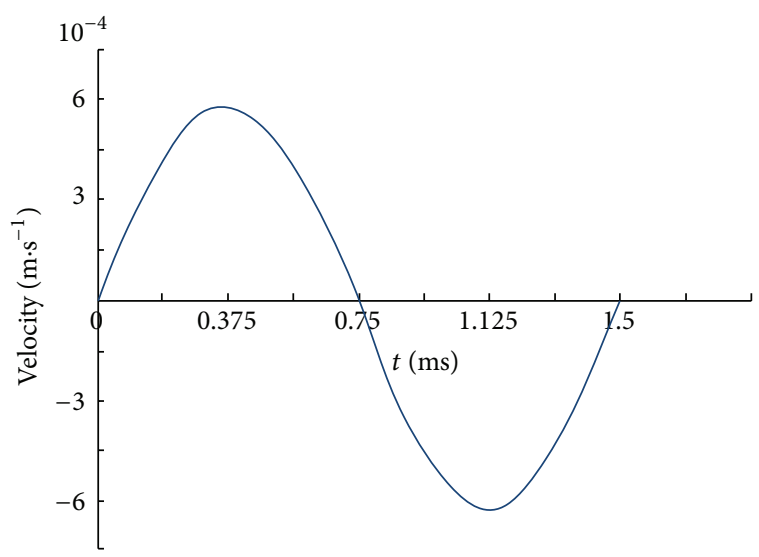

(b) Harmonic stress waves

FIGURE 6: Impact stress wave curves.

along the vertical direction at the middle of the roadway roof to monitor the change of elastic strain energy. The simulation schemes are as follows.

Scheme 1. After the static calculation reaches equilibrium, impact stress waves are imposed on the boundary between the elastic region and the plastic region at the midline above the roadway roof for subsequent dynamic calculation. This scheme aims to simulate the propagation of impact energy in the non-blast-damage zone.

Scheme 2. After reaching equilibrium, the $\mathrm{ABDZ}$, to a range of $2 \mathrm{~m}$, is set on the boundary between the elastic region and the plastic region of the roadway roof according to published data [17] (Figure 7). When the static calculation reaches equilibrium for a second time, the impact stress waves are applied on the boundary between the elastic region and the $\mathrm{ABDZ}$ at the midline above the roadway roof for subsequent dynamic calculation.

The changes in vertical stress and impact-induced vibration energy in the surrounding rocks were observed at the midline above the roadway roof, so as to analyse the influence of the ABDZ on the impact stress waves and determine the dissipation of the impact-induced vibration energy therein.

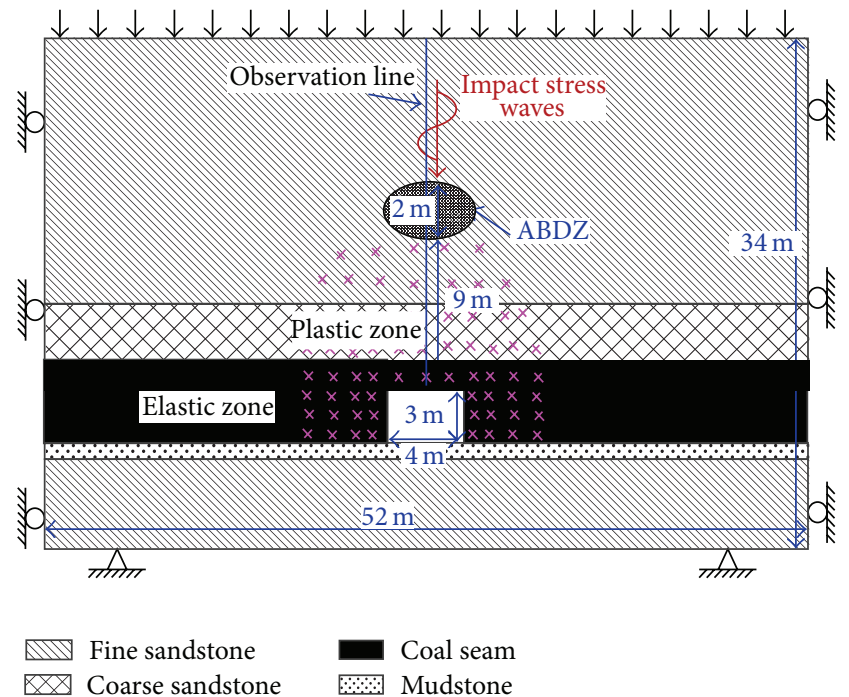

FIgURE 7: Numerical simulation model.

4.3. Dissipation of Impact Stress Waves in the ABDZ. After the static calculation reaches equilibrium, the plastic region (including the fractured region) is approximately $9 \mathrm{~m}$ thick 


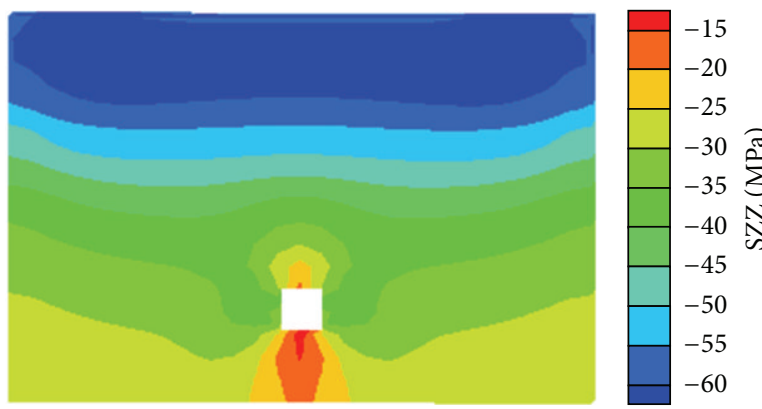

(a) Action time $t=1 \mathrm{~ms}$

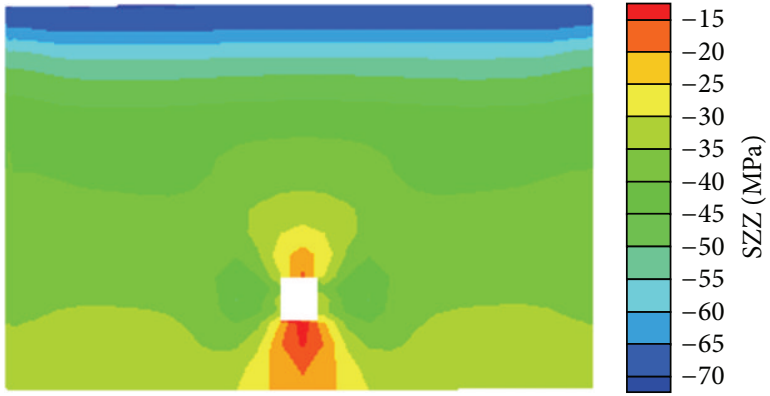

(b) Action time $t=2 \mathrm{~ms}$

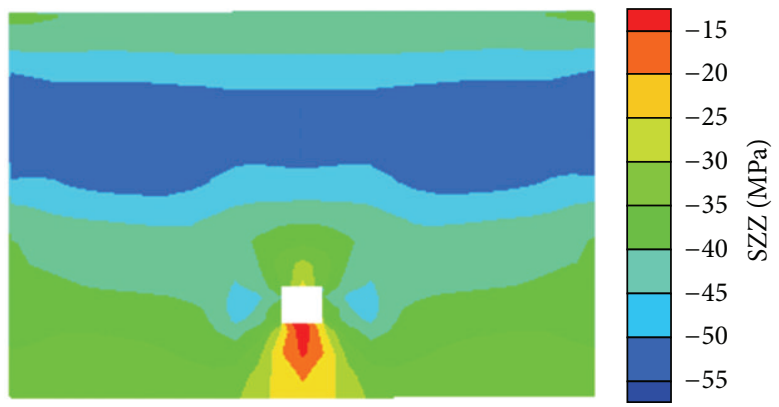

(c) Action time $t=3 \mathrm{~ms}$

FIGURE 8: Numerical simulation of vertical stress in the surrounding rocks: Scheme 1.

on the roof of the roadway. Then, according to Scheme 1, the impact stress waves are applied to the zone (the interface between the elastic and the plastic regions) at a distance of $9 \mathrm{~m}$ from the surface of the roadway roof. According to Scheme 2, the blasting damage zone lying within a range of $2 \mathrm{~m}$ was set in the boundary between the elastic and the plastic regions at the midline above the roadway roof: the impact stress waves were then imposed on the boundary between the elastic region and the blasting damage zone (Figure 7).

The variations in vertical stress and impact-induced vibration energy of the unit body in the surrounding rocks illustrated in Schemes 1 and 2 are shown in Figures 8-12.

(1) The Change of Vertical Stress in the Surrounding Rocks under the Action of the Impact Stress Waves. Under the influence of the impact stress waves for the $3 \mathrm{~ms}$, the change in vertical stress in the surrounding rocks is shown in Figures 8-11.

The vertical stress in the roadway roof is large at $t=2 \mathrm{~ms}$. It can be explained by the fact that the compression and tension waves are contained within one period of the impact stress waves. The vertical stress in the surrounding rocks is large under the action of the compression wave, while it is expected to decrease when affected by the tension wave. At $t=2 \mathrm{~ms}$, according to Scheme 1 , the vertical stress, at approximately $9 \mathrm{~m}$ above the roadway roof, reaches $70 \mathrm{MPa}$, with a stress concentration factor of 2.8 , while the vertical stress decreases gradually from a point $9 \mathrm{~m}$ above the roadway roof to $2 \mathrm{~m}$ above it, with the decreasing amplitude per unit length being $6.14 \mathrm{MPa}$. The decreasing amplitude is approximately $10 \mathrm{MPa} \cdot \mathrm{m}^{-1}$ from $2 \mathrm{~m}$ above the roadway roof to the roadway surface (Figure 9). In contrast, the maximum vertical stress at the boundary between the $\mathrm{ABDZ}$ and the elastic zone in the roadway surrounding rocks $(11 \mathrm{~m}$ above the roof at $t=$ $2 \mathrm{~ms}$ ) is about $70 \mathrm{MPa}$ in Scheme 2. However, Figure 11 shows the decreasing amplitude of the vertical stress in the ABDZ of the surrounding rocks to be approximately $15 \mathrm{MPa} \cdot \mathrm{m}^{-1}$. Furthermore, the decreasing amplitudes of the vertical stress are $2.85 \mathrm{MPa} \cdot \mathrm{m}^{-1}$ from $9 \mathrm{~m}$ to $2 \mathrm{~m}$ above the roof and $10 \mathrm{MPa} \cdot \mathrm{m}^{-1}$ approximately from $2 \mathrm{~m}$ above the roof to the roadway surface, separately.

(2) The Dynamic Response of the Impact-Induced Vibration Energy in the Surrounding Rocks under the Action of the Impact Stress Waves. Figure 12 shows the dynamic response of the impact-induced vibration energy at the medial axis of the roadway roof under the effect of the impact stress waves. For Scheme 1, the impact-induced vibration energy is large (248.6 kJ at $9 \mathrm{~m}$ above the roof), while it decreases gradually from $9 \mathrm{~m}$ to $2 \mathrm{~m}$ above the roof at $20 \mathrm{~kJ} \cdot \mathrm{m}^{-1}$. The impactinduced vibration energy close to the roadway surface is approximately $30 \mathrm{~kJ}$, where a rock burst is likely. By contrast, in Scheme 2, the impact-induced vibration energy shows a maximum decreasing amplitude in the ABDZ, being approximately $40 \mathrm{~kJ} \cdot \mathrm{m}^{-1}$. The decreasing amplitude of the impactinduced vibration from $9 \mathrm{~m}$ to $2 \mathrm{~m}$ above the roof is basically the same as that in Scheme 1. The impact-induced vibration energy near the roadway is approximately $2 \mathrm{~kJ}$, which is far smaller than the threshold value $(25 \mathrm{~kJ})$ for the occurrence of a rock burst [18].

According to the comparative analysis of the dynamic responses of the vertical stress and the impact-induced vibration energy in the roadway surrounding rocks with, and 


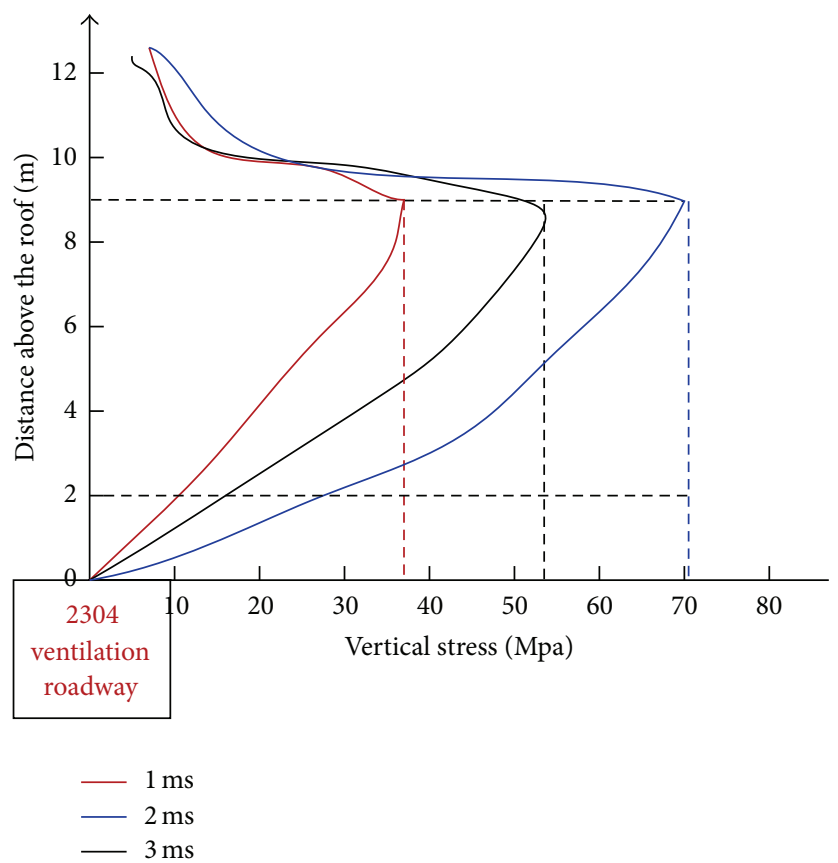

FIGURE 9: The change in vertical stress in the surrounding rocks: Scheme 1.

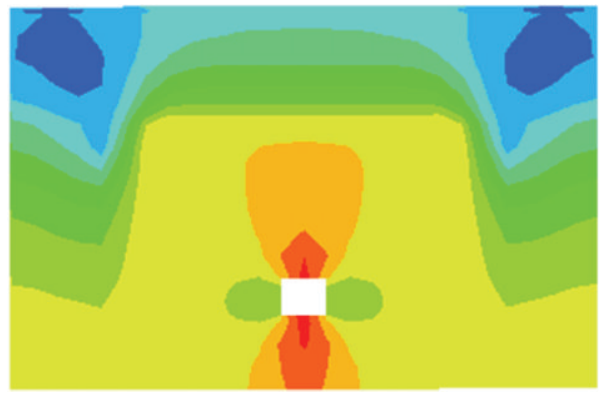

(a) Action time $t=1 \mathrm{~ms}$

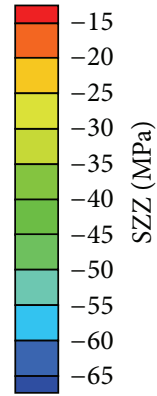

$-65$

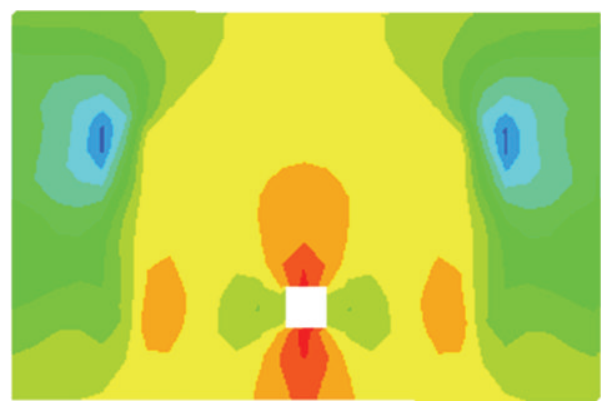

(c) Action time $t=3 \mathrm{~ms}$

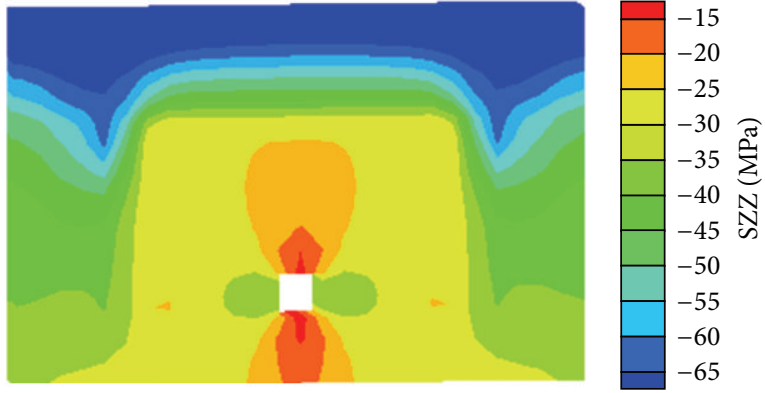

(b) Action time $t=2 \mathrm{~ms}$

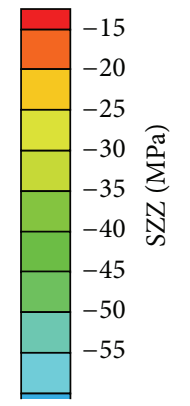

FIGURE 10: Dynamic response of the vertical stress in the surrounding rocks: Scheme 2.

without, the $\mathrm{ABDZ}$, under the action of impact stress waves, the following conclusions can be obtained: under the action of the impact stress waves, the vertical stress and the impactinduced vibration energy within the roadway surrounding rocks are increased significantly (Figures $8-12$ ). When the impact stress waves are propagated to the roadway surface through the ABDZ of the surrounding rocks, most of the impact-induced energy is dissipated in the form of heat energy, surface energy, and plastic energy [19]. This is because the $\mathrm{ABDZ}$ is a fractured structure consisting of multiple joints and fractures, and the impact-induced vibration energy leads to the dislocation, extrusion, and repeated damage of the fractured rock masses $[20,21]$. As a result, the impact-induced vibration energy is weakened substantially 


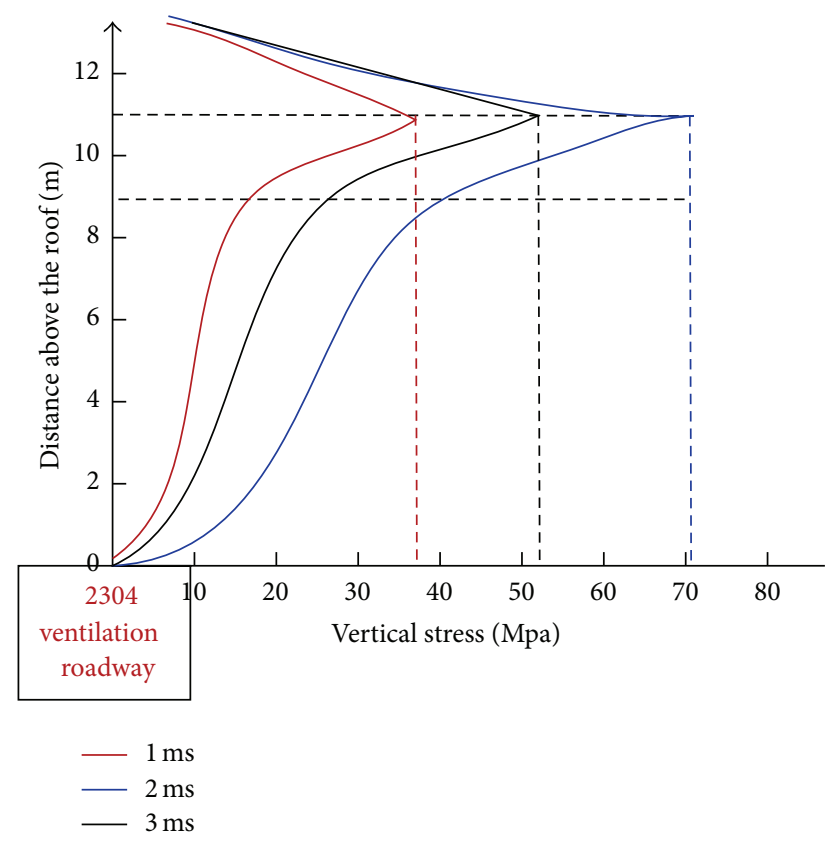

FIGURE 11: Change in vertical stress in the surrounding rocks: Scheme 2.

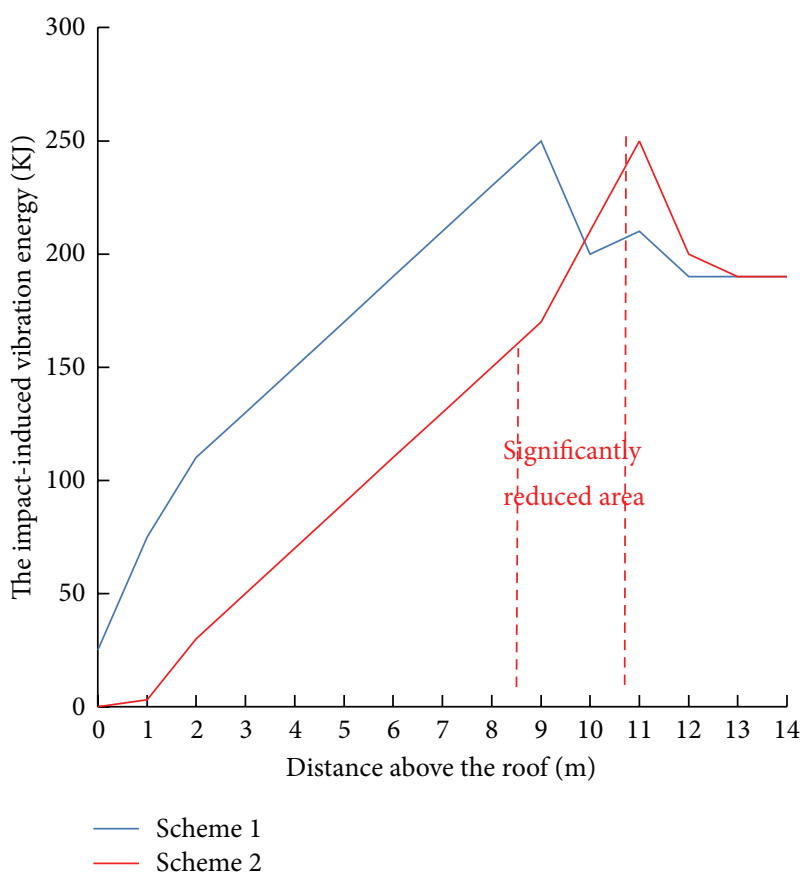

FIGURE 12: Dynamic response of the impact-induced vibration energy of the strata in the roadway roof.

to generate a reduced stress zone in the ABDZ. Meanwhile, the impact-induced vibration energy within the anchorage zone of the surrounding rocks is reduced accordingly (the area situated within $9 \mathrm{~m}$ to $11 \mathrm{~m}$ above the roadway roof in Figure 12). Therefore, the proposed Scheme 2 can effectively reduce the impact-induced vibration energy.

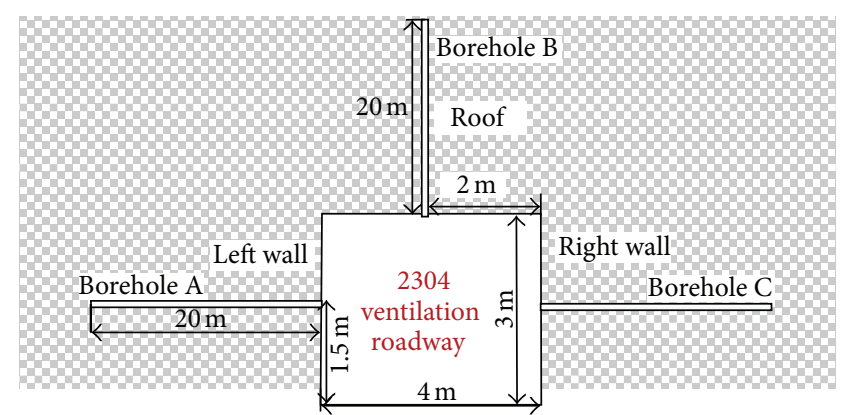

Figure 13: Borehole layout.

\section{Application Example}

5.1. Field Condition and the Setting of the ABDZ. The observation stations were established at $138 \mathrm{~m}$ (station 1), $160 \mathrm{~m}$ (station 2), and $182 \mathrm{~m}$ (station 3 ) from the ventilation roadway of the 2304 working face in the Tangkou coal mine (Figure 4). A high-power pneumatic drill was used to drill five boreholes in the two walls and roof of the roadway (Figure 13): the length and diameter of the boreholes were $20 \mathrm{~m}$ and $42 \mathrm{~mm}$, respectively. The method of drill bit analysis was used to determine the energy concentration zone in the surrounding rocks. Since the surrounding rocks from $1 \mathrm{~m}$ to $3 \mathrm{~m}$ depth into the roadway sides are already damaged, the cuttings obtained from depths of 1 to $3 \mathrm{~m}$ in the boreholes were abandoned in the field. Samples were therefore cut from no less than $4 \mathrm{~m}$ deep. The test results are shown in Figure 14.

As shown in Figure 14, at borehole depths of 9 to $10 \mathrm{~m}$, the cuttings index of the boreholes reaches a maximum $(4.1 \mathrm{~kg} / \mathrm{m})$. This indicates that strong elastic strain energy is contained herein; however, if the elastic strain energy is disturbed by the mining of the excavated working face, it is likely to generate intensive impact stress waves and even give rise to a rock burst. This is because the anchorage support system and the roadway surrounding rocks themselves are not enough to resist the impact-induced vibration energy.

To reduce the possibility of a rock burst in the 2304 ventilation roadway, a drilling rig was used to drill a borehole (length, $9 \mathrm{~m}$ and radius, $0.75 \mathrm{~m}$ ) in the surrounding rocks. Soon afterwards, a spherical explosive cartridge was used to conduct coupling blasting, on the one hand, to transfer the concentration zone of the elastic strain energy to the deeper surrounding rocks. On the other hand, it aims to form an ABDZ, in which the fractured coal and rock masses can dissipate some of the impact-induced vibration energy (Figure 15). Immediately after the explosion, lengthened anchor cables, $15 \mathrm{~m}$ long, were installed in the two walls and roof of the roadway (Figure 16).

5.2. Impact Resistance of the 2304 Ventilation Roadway. To verify the dissipation effect of the ABDZ on the impactinduced vibration energy, the method of drill bit analysis was performed on the aforementioned observation stations $(1,2$, and 3 in Figure 4) to determine the cuttings index of the borehole in roadway surrounding rocks (Figure 17). By establishing the $\mathrm{ABDZ}$ in the 2304 ventilation roadway, the cuttings 


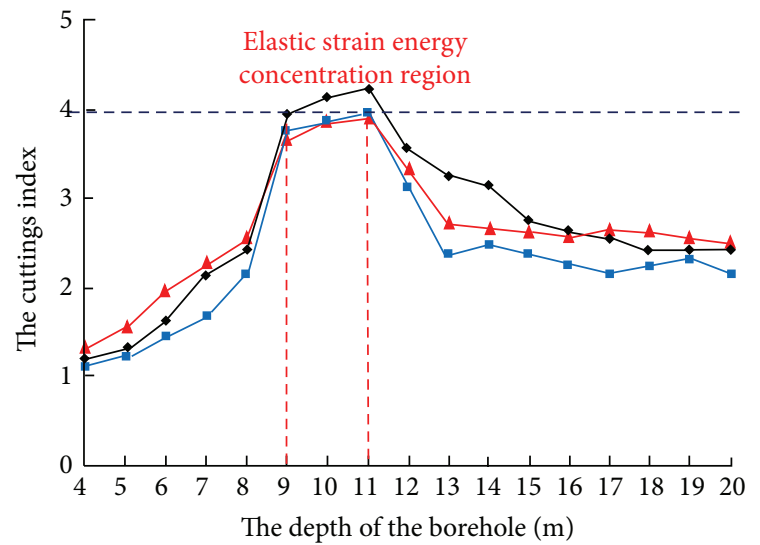

- Borehole A

$\rightarrow$ Borehole B

$\neg$ Borehole C

(a) Observation station 1

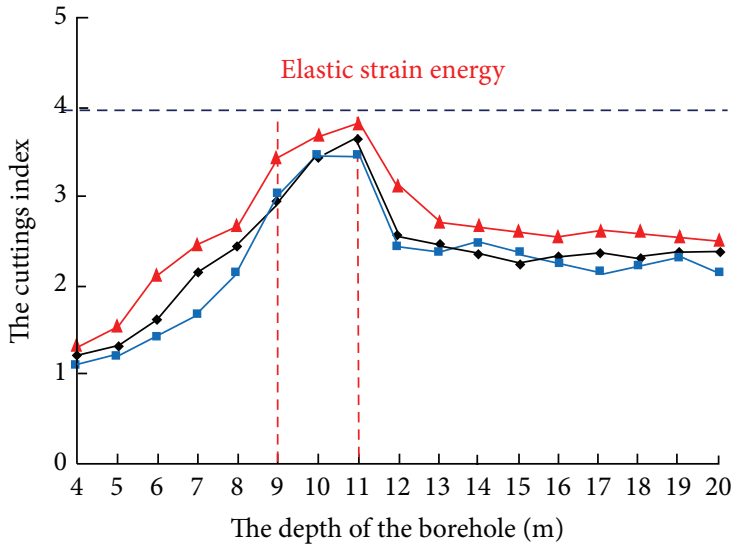

$\longleftarrow$ Borehole A
$\longleftarrow$ Borehole B
$\longleftarrow$ Borehole C

(b) Observation station 2

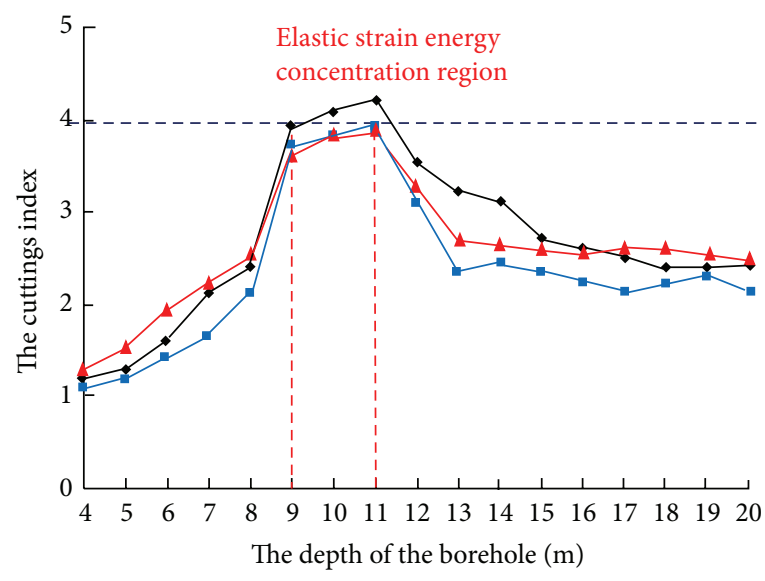

$\rightarrow$ Borehole A

$\rightarrow$ Borehole B

$\leftarrow$ Borehole C

(c) Observation station 3

FIgURE 14: Test results: cuttings index.

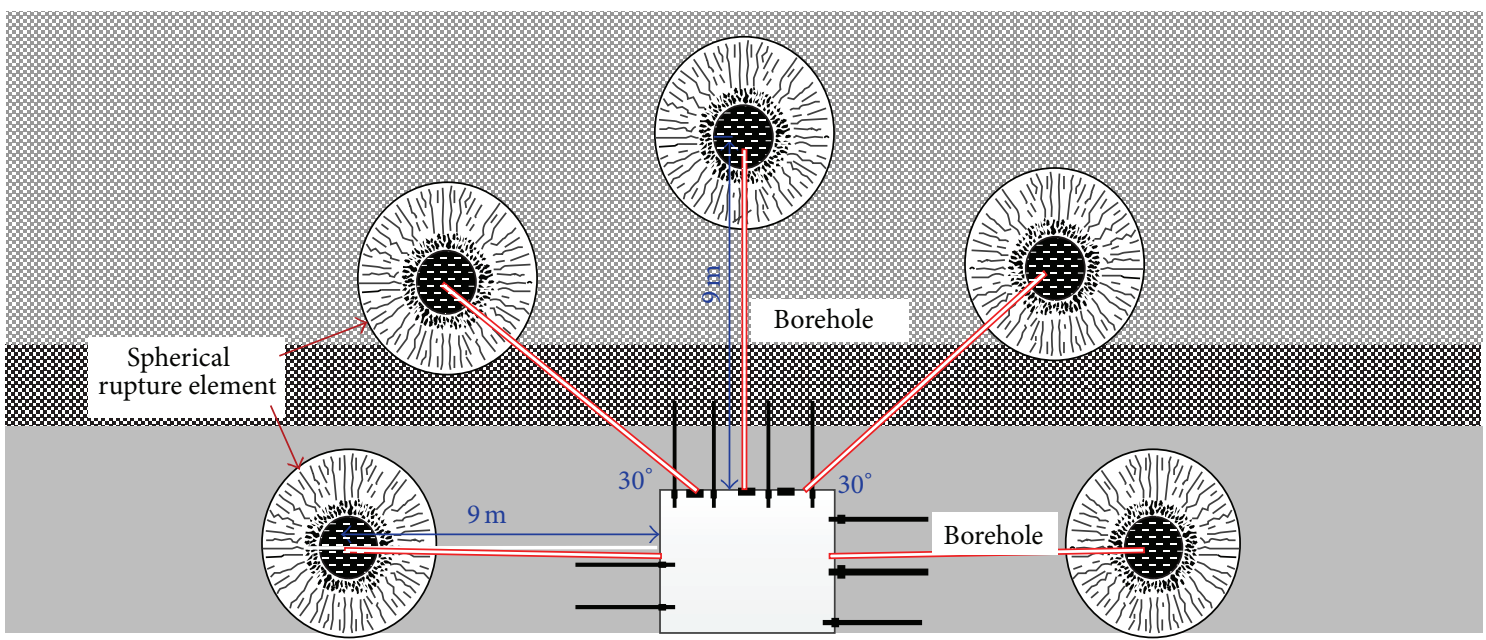

FIGURE 15: Working drawing of the pressure relief and blasting operations: number 2304 roadway. 


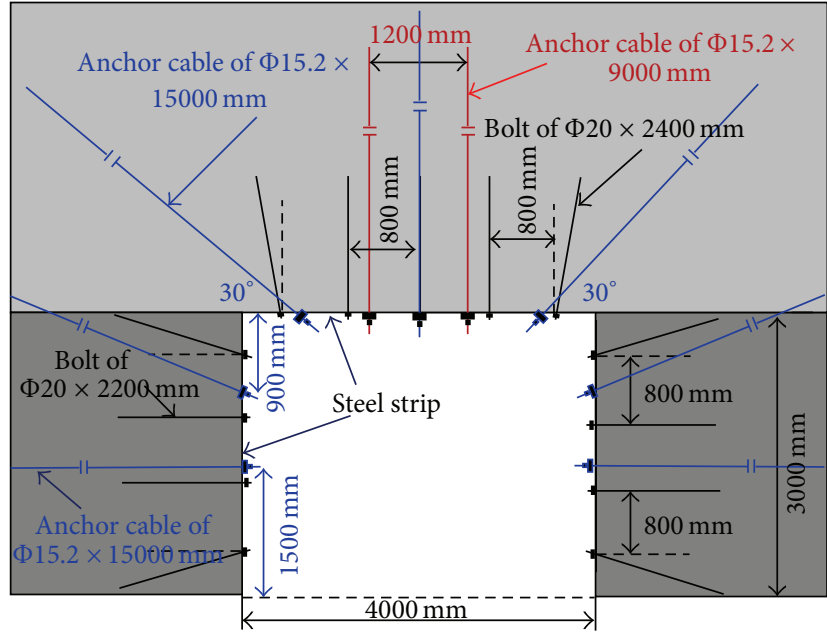

(a) Plan view

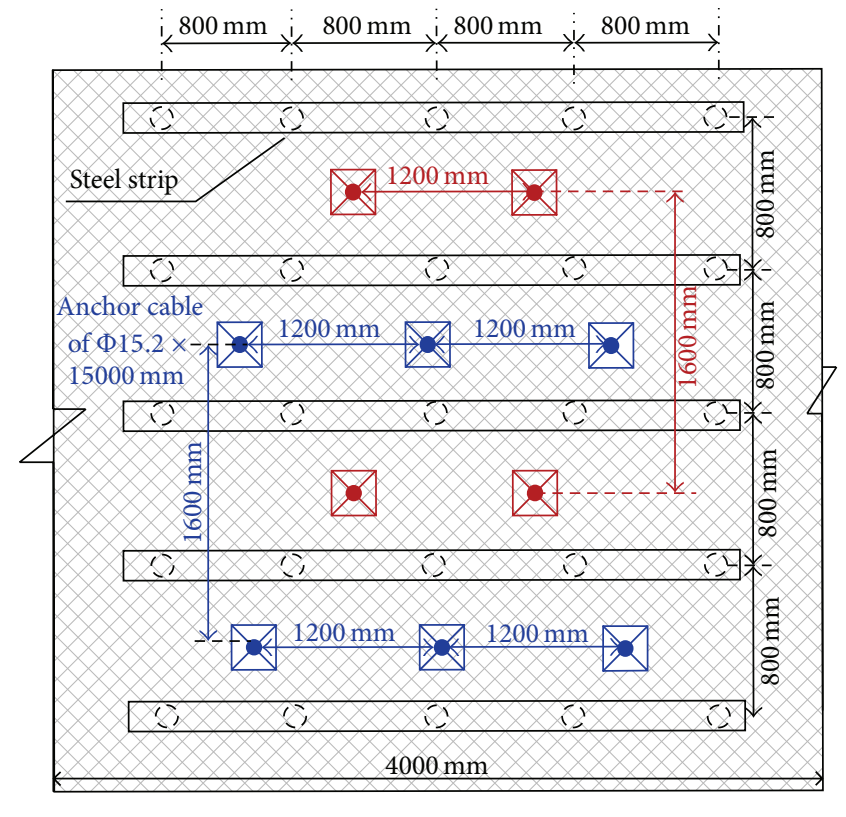

(b) Top view

FIGURE 16: Improved bolt support system.

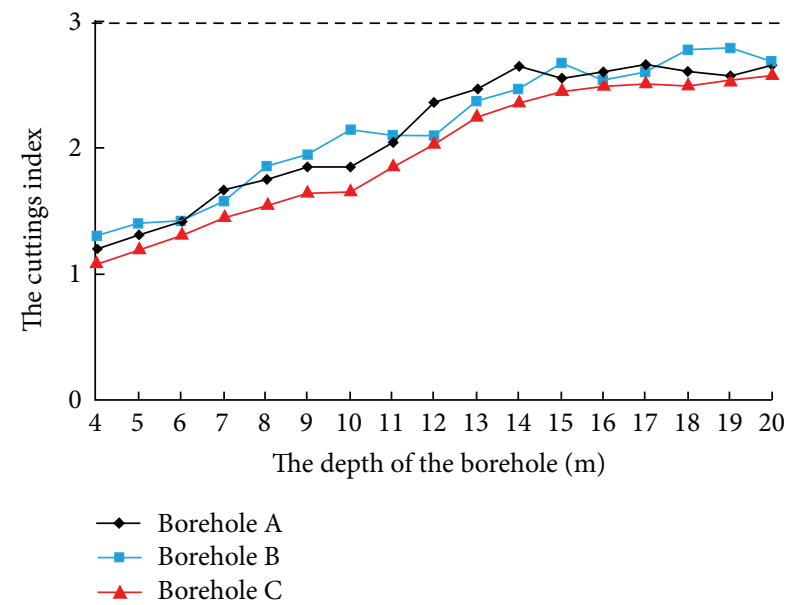

(a) Observation station 1

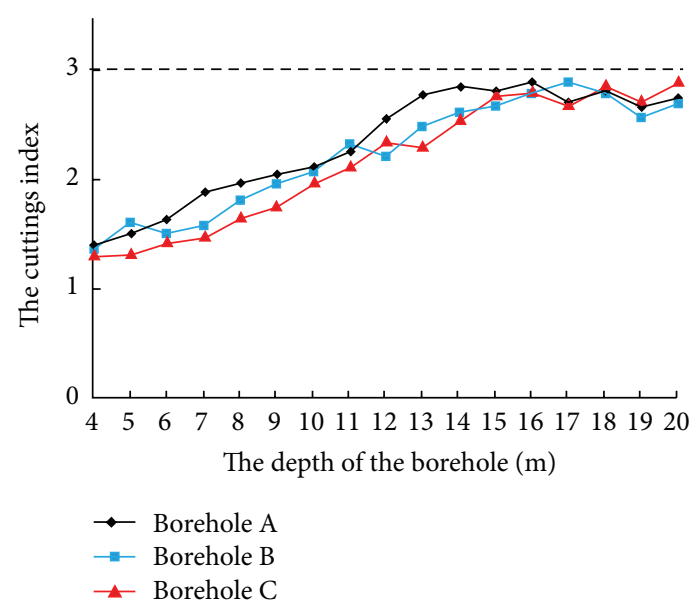

(b) Observation station 2

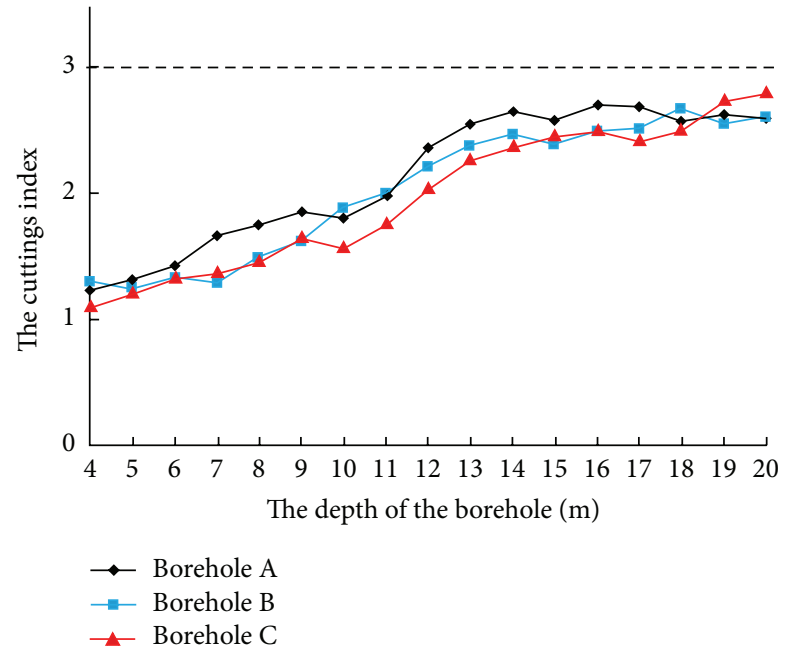

(c) Observation station 3

FIGURE 17: Test results: cuttings index. 
index of the boreholes in the surrounding rocks is reduced, with the maximum decrease being approximately 33\%. That is, the elastic strain energy in the surrounding rocks of the deep roadway is reduced. Meanwhile, by increasing the number of anchorage cables, the resistance of the anchorage support system in the roadway, to prevent impact-induced vibration energy, is strengthened, which gives rise to a significantly improved impact resistance of the deep roadway. As demonstrated in the field monitoring, no rock burst was found in the 2304 ventilation roadway from November, 2012, to November, 2013, and there was little deformation of the surrounding rocks. Therefore, the 2304 ventilation roadway satisfies the mine ventilation, human entry, and transportation requirements.

\section{Conclusions}

(1) While establishing the artificial blasting damage zone in the surrounding rocks of the deep roadway, the pulverizing zone, fractured zone, and crack zone are expected to be generated in the blasting damage zone to form the spherical rupture element. When the elastic strain energy within the surrounding rocks of the deep roadway is disturbed, it is expected to be propagated through the rock mass in the form of impact stress waves. Thereafter, the stress waves are supposed to pass through the crack zone, fractured zone, and pulverizing zone of the spherical rupture element in sequence and then pass through these zones again in the opposite order, last to enter the anchorage zone of the roadway.

(2) A numerical simulation was used to study the changes in vertical stress and elastic strain energy in the surrounding rocks under the action of the impact stress waves. As demonstrated by the simulation results, while establishing the blasting damage zone in the rocks surrounding this deep roadway, the decreasing amplitudes of the vertical stress and the impactinduced vibration energy in the blasting damage zone are $15 \mathrm{MPa} \cdot \mathrm{m}^{-1}$ and $40 \mathrm{KJ} \cdot \mathrm{m}^{-1}$, respectively.

(3) As demonstrated by the case study, the establishment of the ABDZ in the rocks surrounding this deep roadway and the enhancement of the anchorage support system have strengthened the ability to prevent impact-induced vibration energy. Meanwhile, the effect of the impact-induced vibration energy on the anchorage support system of the roadway is reduced, which gives rise to the significantly increased impact resistance of this deep roadway.

\section{Competing Interests}

The authors declare that they have no competing interests.

\section{Acknowledgments}

This study was supported by National Natural Science Foundation of China (nos. 51574154, 51274133, and
51344009), Shandong Province Natural Science Fund (no. ZR2010EEZ002), Shandong Province "Taishan Scholar" Construction Project Special Fund, Open Fund of State Key Laboratory of Mining Disaster Prevention and Control Cofounded by Shandong Province and the Ministry of Science and Technology (no. MDPC2013KF12), and Postgraduate Innovative Fund Project of Shandong University of Science and Technology (YC150308).

\section{References}

[1] Y. S. Pan, Z. H. Li, and M. T. Zhang, "Distribution, type, mechanism and prevention of rockburst in China," Chinese Journal of Rock Mechanics and Engineering, vol. 22, no. 11, pp. 1844-1851, 2003.

[2] R. G. K. Morrison, "Theory and the practical problem of rock bursts," Engineering and Mining Journal, vol. 149, no. 3, pp. 6672, 1948.

[3] J. G. Ning, X. S. Liu, and Y. L. Tan, "Mechanism of rock-burst prevention by synergizing pressure relief and reinforcement of surrounding rocks with zonal disintegration in deep coal roadway," Disaster Advances, vol. 5, no. 4, pp. 844-850, 2012.

[4] G.-R. Zheng and W.-B. Yang, "Calculation method of the failure zone width of side coal-wall of roadway in seams," Journal of China Coal Society, vol. 28, no. 1, pp. 37-40, 2003.

[5] J. F. Pan, Y. Ning, D. B. Mao, H. Lan, T. Du, and Y. Peng, "Theory of rockburst start-up during coal mining," Chinese Journal of Rock Mechanics and Engineering, vol. 31, no. 3, pp. 586-596, 2012.

[6] J. F. Pan, Y. Ning, Z. H. Qin, S. Wang, and Y. Xia, "Dredging technology of pressure with deep-hole interval blasting based on theory of rock burst start-up," Chinese Journal of Rock Mechanics and Engineering, vol. 31, no. 7, pp. 1414-1421, 2012.

[7] L. Wang, Y. P. Cheng, and F. R. Li, "Fracture evolution and pressure relief gas drainage from distant protected coal seams under an extremely thick key stratum," Journal of China University of Mining and Technology, vol. 18, no. 2, pp. 182-186, 2008.

[8] P. Konicek, K. Soucek, L. Stas, and R. Singh, "Long-hole destress blasting for rockburst control during deep underground coal mining," International Journal of Rock Mechanics and Mining Sciences, vol. 61, pp. 141-153, 2013.

[9] J. Fan, L. Dou, H. He et al., "Directional hydraulic fracturing to control hard-roof rockburst in coal mines," International Journal of Mining Science and Technology, vol. 22, no. 2, pp. 177181, 2012.

[10] Q. X. Qi and L. M. Dou, Theory and Technology of Rock Burst, China University of Mining and Technology Press, Xuzhou, China, 2008.

[11] Y. S. Pan, X. F. Lv, and Z. H. Li, "The model of energy absorbing coupling support and its application in rockburst roadway," Journal of Mining \& Safety Engineering, vol. 28, no. 1, pp. 6-10, 2011.

[12] Y. Z. Liu, Blasting Physical Process of Rock, Metallurgical Industry Press, Beijing, China, 1980.

[13] G.-S. Wang, C.-H. Li, S.-L. Hu, C. Feng, and S.-H. Li, "A study of time-and spatial-attenuation of stress wave amplitude in rock mass," Rock and Soil Mechanics, vol. 31, no. 11, pp. 3487-3492, 2010.

[14] M. Y. Wang and Q. H. Qian, "Attenuation law of explosive wave propagation in cracks," Chinese Journal of Rock Mechanics and Engineering, vol. 17, no. 2, pp. 42-46, 2010. 
[15] Q. Zhang, "Transfer process of stress wave at the joints," Journal of Geotechnical Engineering, vol. 8, no. 6, pp. 99-105, 1986.

[16] X. F. Lv, Y.S. Pan, and J. P. Tang, "Similar material simulation test and numerical analysis of impact damage law of roadway under interaction between coal and support," Rock and Soil Mechanics, vol. 33, no. 2, pp. 604-610, 2012.

[17] C.-P. Lu, G.-J. Liu, H.-Y. Wang, and J.-H. Xue, "Numerical investigation of rockburst effect of shock wave on underground roadway," Shock and Vibration, vol. 2015, Article ID 867582, 10 pages, 2015.

[18] Y. Li, Z. Zhu, B. Li, J. Deng, and H. Xie, "Study on the transmission and reflection of stress waves across joints," International Journal of Rock Mechanics and Mining Sciences, vol. 48, no. 3, pp. 364-371, 2011.

[19] C.-P. Lu and L.-M. Dou, "The relationship between vertical stress gradient, seismic, and electromagnetic emission signals at Sanhejian coal mine, China," International Journal of Rock Mechanics and Mining Sciences, vol. 70, pp. 90-100, 2014.

[20] X. Fu, Q. Sheng, Y. Zhang, and J. Chen, "Application of the discontinuous deformation analysis method to stress wave propagation through a one-dimensional rock mass," International Journal of Rock Mechanics and Mining Sciences, vol. 80, pp. 155-170, 2015.

[21] Y.-L. Tan, Z. Zhang, and C.-L. Ma, "Rock burst disaster induced by mining abutment pressure," Disaster Advances, vol. 5, no. 4, pp. 378-382, 2012. 


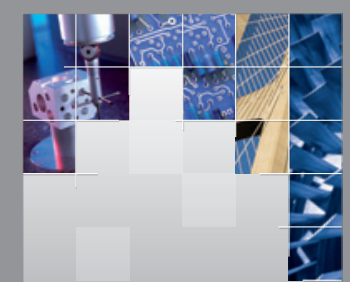

\section{Enfincering}
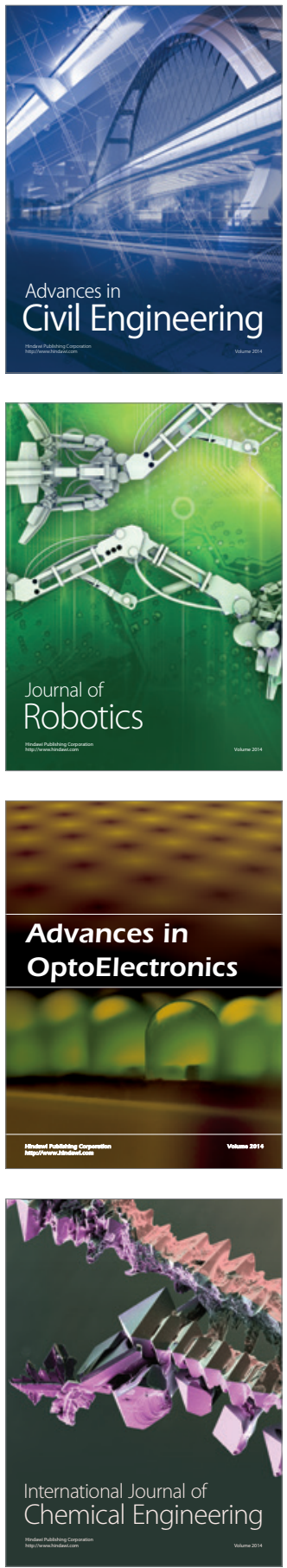

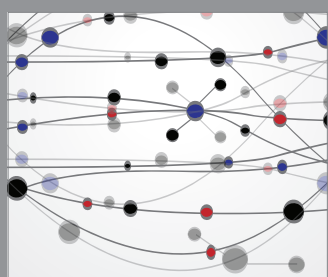

The Scientific World Journal

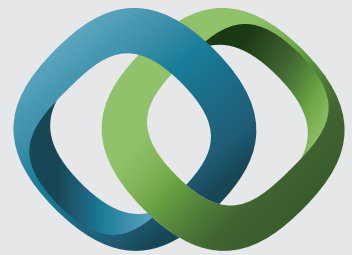

\section{Hindawi}

Submit your manuscripts at

http://www.hindawi.com
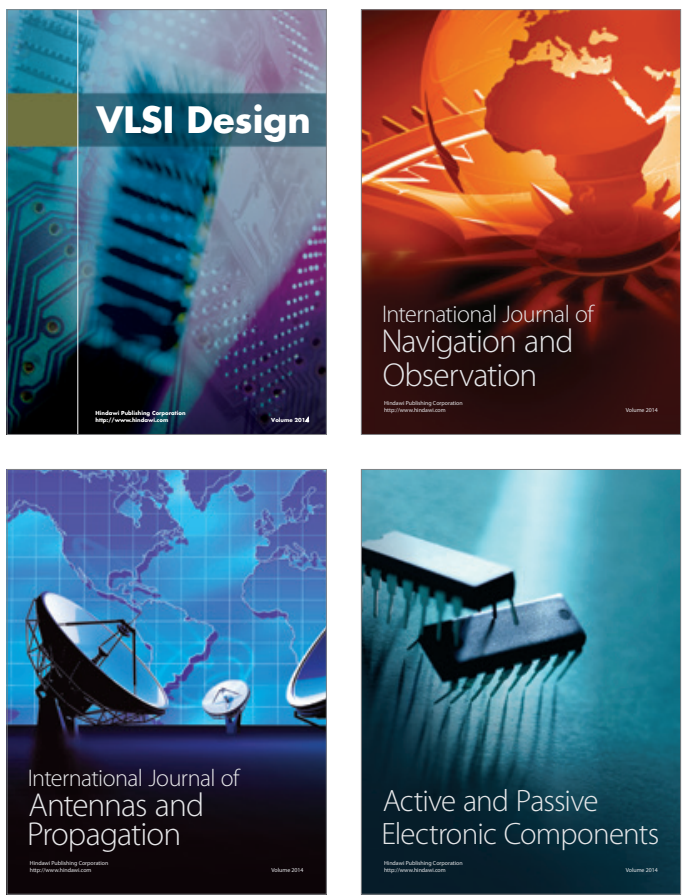
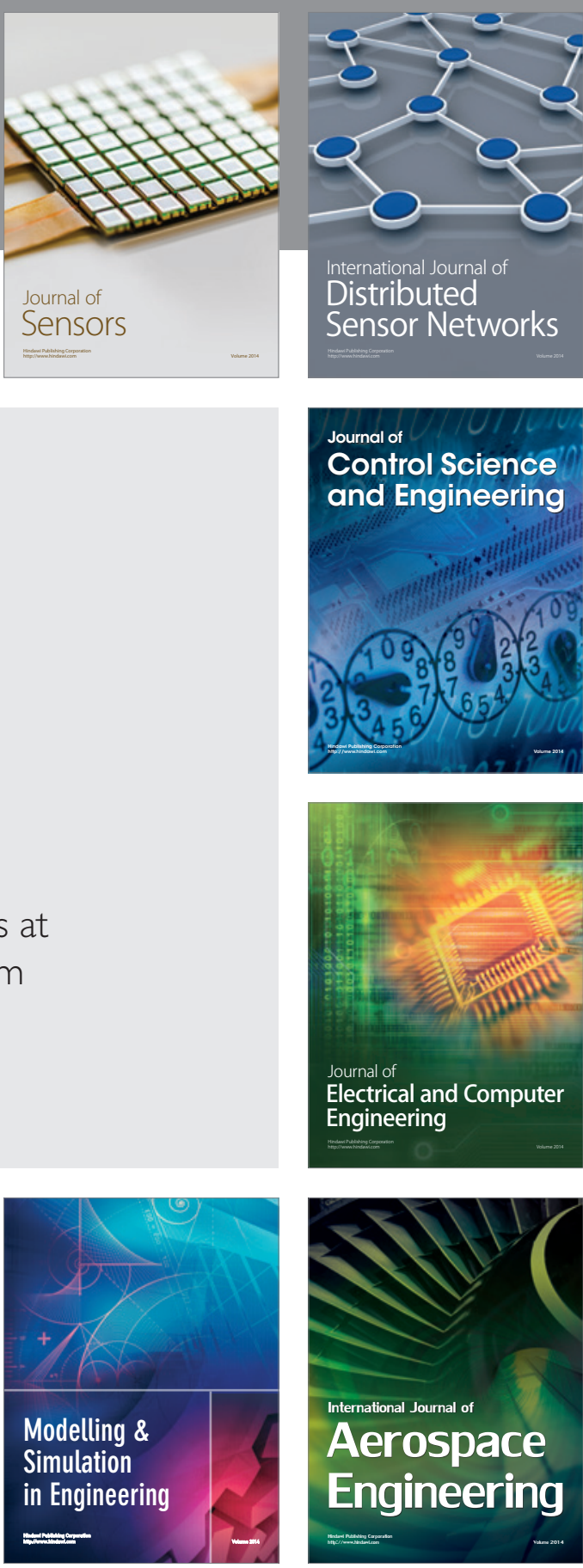

International Journal of

Distributed

Sensor Networks

Journal of

Control Science

and Engineering
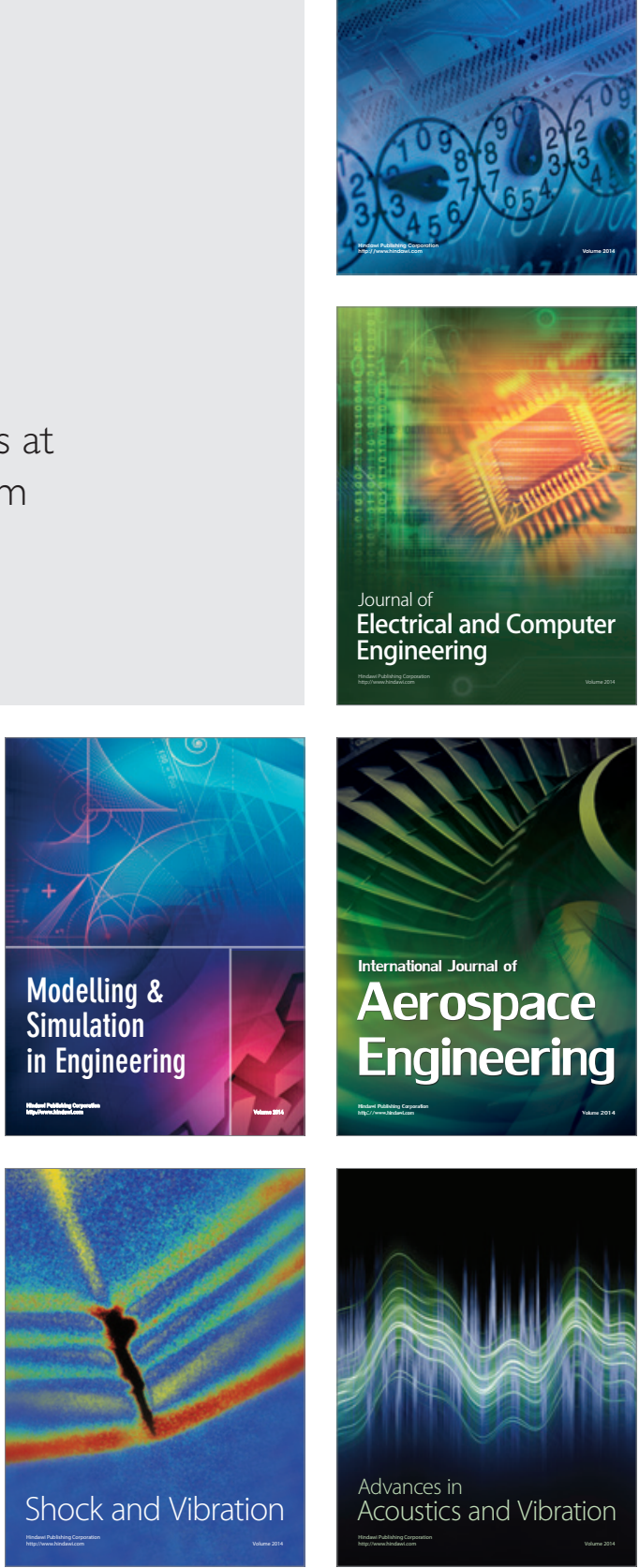